(C) The Author(s) 2019. This is an Open Access article, distributed under the terms of the Creative Commons Attribution-NonCommercial-ShareAlike licence (http://creativecommons.org/licenses/by-nc-sa/4.0/), which permits non-commercial re-use, distribution, and reproduction in any medium, provided the same Creative Commons licence is included and the original work is properly cited. The written permission of Cambridge University Press must be obtained for commercial re-use.

\title{
Crack wave resonances within the basal water layer
}

\author{
Dominik GRÄFF, ${ }^{1}$ Fabian WALTER, ${ }^{1}$ Bradley P. LIPOVSKY ${ }^{2}$ \\ ${ }^{1}$ Laboratory of Hydraulics, Hydrology and Glaciology, ETH Zurich, Switzerland \\ E-mail: graeff@vaw.baug.ethz.ch \\ ${ }^{2}$ Department of Earth and Planetary Science, Harvard University, Cambridge MA, USA
}

\begin{abstract}
Hydraulic processes within and beneath glacial bodies exert a far-reaching control on ice flow through their influence on basal sliding. Within the subglacial system, rapid changes in these processes may excite resonances whose interpretation requires an understanding of the underlying wave mechanics. Here, we explore these mechanics using observations from a kHz-sampled pressure sensor installed in a borehole directly above the hard granite bedrock of a temperate mountain glacier in Switzerland. We apply a previously established theory of wave propagation along thin, water-filled structures such as water-filled voids, basal water layers, or hydraulic fractures. Within such structures, short-wavelength waves experience restoring forces due to compressibility and are composed of sound waves. Long-wavelength resonances, in contrast, experience restoring forces due to elasticity and are composed of anomalously dispersed crack waves or Krauklis waves. Our borehole observations confirm the occurrence of both sound and crack waves within the basal water layer. Using both the resonance frequencies and attenuation of recorded crack waves we estimate thickness, aperture and length of the resonating basal water layer patch into which we drilled. We demonstrate that high-frequency observations of subglacial hydraulic processes provide new insights into this evolving dynamic system.
\end{abstract}

KEYWORDS: glacier hydrology, glacier seismology, subglacial processes

\section{INTRODUCTION}

Subglacial hydrology exerts a significant control on glacier flow. Despite this importance, it is inherently difficult to observe processes at the glacier bed. Therefore numerous studies either concentrate on point measurements directly at the glacier bed through boreholes, or on recordings of signals emitted from hydraulic events acquired with passive seismic techniques. These recordings often show resonances, whose interpretation is challenging (Clarke, 2005; Podolskiy and Walter, 2016). Some studies attribute similar resonance observations in other geological contexts to an intrinsic resonance of hydraulic fractures (Aki and others, 1977) while other studies explain such observations as wave propagation effects (Bean and others, 2014).

Passive seismic observations of such resonances in the cryosphere have often been attributed to resonant waterfilled fractures: Anandakrishnan and Alley (1997) and Winberry and others (2009) found narrow-banded seismic tremor signals from the bed of MacAyeal and Kamb ice streams, Antarctica, respectively, whereas Métaxian and others (2003) detected low-frequency seismic signals from resonant water-filled ice cavities on the flanks of Cotopaxi Volcano, Ecuador. Stuart and others (2005) describe resonances from water-filled fractures close to the glacier base during a surge at Bakaninbreen, Svalbard, and West and others (2010) emphasize the similarity between glacial fracture resonances within Bering Glacier, Alaska, and fluid chambers during an eruption of Augustine Volcano, Alaska.

Related to these observed resonances, rapid short-term fluctuations in water pressure may excite resonances in hydraulic fractures. Such short term fluctuations have been measured in the form of sudden pressure pulses exceeding the ice overburden pressure (Kavanaugh, 2009; Kavanaugh and Moore, 2010) at the bed of Trapridge Glacier, Yukon Territory, Canada. The pulses, measured with pressure sensors in boreholes to the glacier bed, were found to be statistically similar to earthquakes with respect to magnitude and return time distribution, suggesting that the ice/bed interface behaves much like a tectonic fault. In contrast to these sudden pressure pulses, Meierbachtol and others (2018) observed strong sudden pressure drops at the bed of western Greenland's ablation zone, which may imply basal stick-slip motion. Similarly, Rada and Schoof (2018) observed pressure drops on different timescales with occasional instantaneous onsets (i.e., occurring faster than their instrumental sampling rate of 2-20 minutes) on an unnamed Canadian glacier and interpreted them as adjustments of the subglacial drainage system. They concluded that the seasonal evolution of the basal hydraulic system is not gradual, but instead occurs in rapid, discrete switching/ shutoff events.

Thin basal water layers play an important role within the subglacial hydrological system. Although a variety of components (i.e. channels, canals, and linked cavities forming conduits) may act in concert in this system, basal water layers are particularly important because they separate basal ice from bedrock. Weertman (1972) argued that a basal water layer is inherently unstable, whereas Creyts and Schoof (2009) showed that bed protrusions such as clasts can support the ice above the water layer by bridging the water gap, thereby leading to stable conditions for basal drainage at low gradient glaciers. Hydraulic processes and conditions associated with this water layer have a profound influence on ice dynamics. Basal water layers have the ability to reduce the effective roughness of the glacier bed (Walder, 1982; Iverson, 1999), leading to larger sliding rates. 
Likewise, high water pressures reduce the shear stress that is transmitted to the bed and thus increase basal sliding (Clarke, 2005). Despite its physical importance for ice dynamics, however, direct evidence for the subglacial water layers underneath temperate glaciers in natural environments is rare. Even with experiments using artificial till in the subglacial laboratory at Engabreen, Norway, Iverson and others (2007) could not observe the basal water layer directly. However, they could determine the thickness of the water layer at the ice/till interface from spatial water pressure variations and water discharge measurements during pumping experiments.

Basal water layers are geometrically similar to hydraulic fractures in that they both consist of thin water layers in an otherwise solid medium. This geometrical similarity therefore suggests that the same kind of water resonance phenomena may occur in both environments. (Lipovsky and Dunham, 2015). There exist two end-members of wave types occurring in these fracture-like systems. In the short-wavelength limit, the ice and rock walls of the water layer are nearly rigid compared to the compressibility of water, and waves propagate as sound waves. The other end-member is the long-wavelength limit where the fluid is nearly incompressible and where waves within the fractures propagate slower at longer wavelength due to a corresponding decrease of fracture wall compliance. These waves are known as crack waves or Krauklis waves (Krauklis, 1962; Ferrazzini and Aki, 1987). By using resonances that are excited by counter-propagating crack waves within fluid-filled fractures or local patches of the basal water layer, in theory, the geometry of such a fluid-filled void can be inferred from the fundamental frequency of the resonances and the attenuation of the oscillation, which is a result of the fluid viscosity and the emitted seismic radiation.

In a linearized model that accounts for quasi-static elastic deformation of the fracture walls, fluid viscosity, inertia and compressibility, and which is valid for wavelengths greater than the crack aperture, Lipovsky and Dunham (2015) describe wave motion along a thin, fluid-filled crack. The authors derive the fracture geometry from the resonance frequency $f$ and quality factor $Q$ reflecting the attenuation of the resonance. The length of the crack $L$ is inversely proportional to the square root of the fundamental frequency $f_{1}$ and the third root of the width of the fundamental frequency peak $\Delta f_{1}$ :

$$
L \propto f_{1}^{-1 / 2} \Delta f_{1}^{-1 / 3}
$$

The crack aperture is proportional to the square root of the fundamental frequency peak and inversely proportional to the width of the fundamental frequency peak:

$$
w \propto \sqrt{f_{1}} \Delta f_{1}^{-1}
$$

These proportionalities are derived from Eqns (3) and (4) of Lipovsky and Dunham (2015) and the signal attenuation $Q_{1}=f_{1} \Delta f_{1}^{-1}$ assuming a signal decay of $e^{-f_{1} t / 2 Q_{1}}$. The exact equations for the crack wave limit, in which the fluid is incompressible and the fracture walls are deformable, can be found in Appendix A.

Despite remote observations of radiated seismic waves, direct measurements of crack waves within or in close vicinity to their resonance body do not exist for glaciers. Similarly, no direct evidence exists for an extended macroscopic water layer in a non-artificial environment underneath temperate glaciers. Here, we go beyond previous studies of crack waves in glaciers and ice streams (Anandakrishnan and Alley, 1997; Winberry and others, 2009; Métaxian and others, 2003; Stuart and others, 2005; West and others, 2010) by measuring hydraulic resonances directly within the basal water layer of an Alpine glacier. To this end, we deployed a $\mathrm{kHz}$-sampled pressure sensor at the bottom of a borehole drilled to the glacier base. We thus resolve the source-path ambiguity of the previously mentioned seismic studies, and show that resonant wave motion in fractures occurs as a source effect. By applying the crack wave model described in Lipovsky and Dunham (2015) to the measured resonant frequencies, we estimate the spatial extension, thickness and temporal changes of the basal water layer in the direct vicinity of the borehole site. Our results show that macroscopic basal water layers are patchy enough to provide resonance volumes that are sufficiently delimited from the remaining water layer.

\section{FIELD SITE AND DATA ACQUISITION}

Our study site is the tongue of Rhonegletscher in the Swiss Alps, where we monitored basal water pressure in a single borehole between 17 August 2017 and 24 August 2017. Rhonegletscher is a temperate glacier in central Switzerland with an area of $\sim 15.5 \mathrm{~km}^{2}$ and a length of $\sim 8 \mathrm{~km}$. It flows southward from 3600 to $2200 \mathrm{~m}$ a.s.I. (GLAMOS, 2018) leading to an average surface slope of $10^{\circ}$ (see Fig. 1).

The study site in 2017 (red dot in Fig. 1) is located at the lowest $10 \%$ of the tongue at $\sim 2300 \mathrm{~m}$ altitude close to the flow line at LV03: 672750, 159950. A piezoresistive pressure sensor with a sampling frequency of $1 \mathrm{kHz}$ was installed $\sim 10$ $\mathrm{cm}$ above the glacier bed in a $(117 \pm 1) \mathrm{m}$ deep borehole, drilled with the hot water technique (Iken and others, 1976). The total time over which the pressure sensor recorded at the bed of the glacier is 51 hours excluding multiple recording interruptions. Further specifications of the instrumentation and experiment setup as well as times of data acquisition can be found in the Supplementary material.

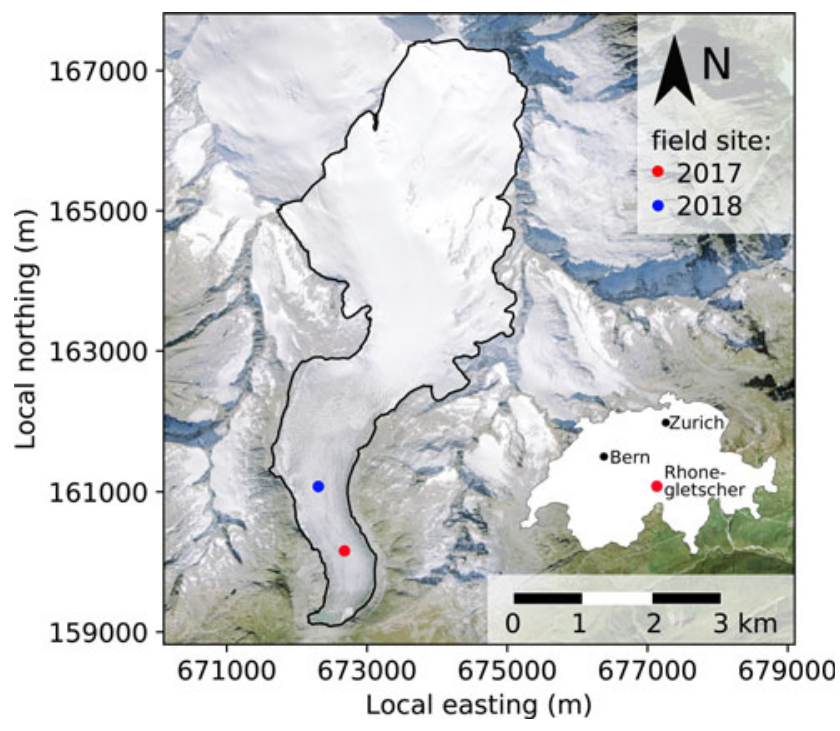

Fig. 1. Map of Rhonegletscher and its location within Switzerland (white polygon). The red dot indicates the field site in 2017, the blue one in 2018. Coordinates in LV03. (Ortho-image provided by Swisstopo and glacier outline in 2007 (Bauder and others, 2007)) 

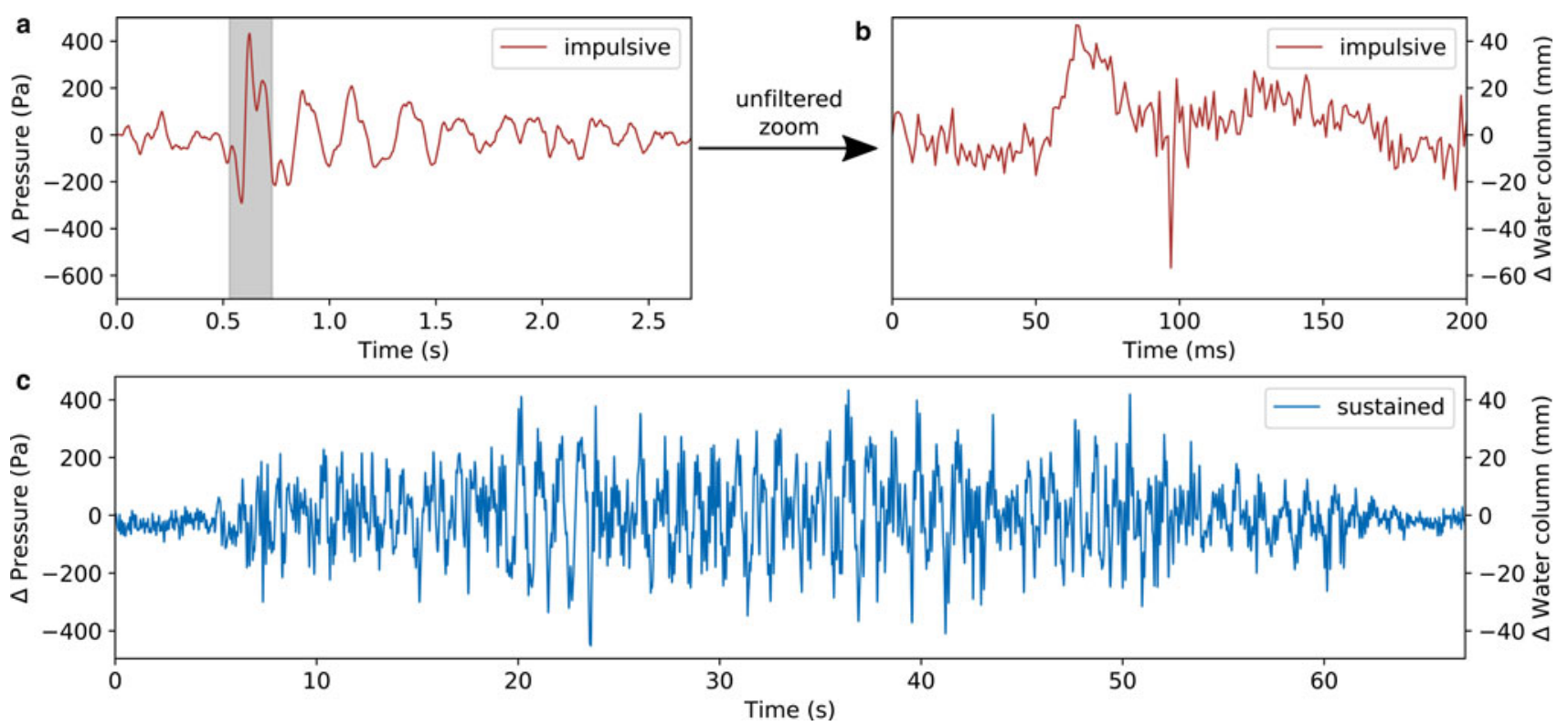

Fig. 2. (a) Waveform of an impulsive resonance event low pass filtered at $10 \mathrm{~Hz}$. (b) Unfiltered zoom into the gray marked area of subplot (a). A non-dispersive sound wave becomes visible at $\sim 90 \mathrm{~ms}$. (c) Waveform of a sustained resonance event low pass filtered at $10 \mathrm{~Hz}$.

\section{HYDRAULIC OSCILLATIONS AT THE GLACIER BED}

We visually scanned the recorded pressure time series and found different types of transient signals. Here, we note four types of events: The first two are non-resonant ones and include repeatedly occurring swarms of high frequency $(250 \mathrm{~Hz})$ pressure pulses, as well as slow pressure drops lasting longer than a second. The other two end-members are resonance phenomena. Among them, we find short resonances decaying within a few seconds (see Fig. 2a). These signals show a dominant frequency of $\sim 4 \mathrm{~Hz}$ and we call them 'impulsive' events. Moreover, the record contains resonant signals lasting roughly one minute long (see Fig. 2c) with a dominant frequency of $\sim 1 \mathrm{~Hz}$, which we call 'sustained' events. While all sustained events show a rather gradual emergence and decay, impulsive events often show a gradual decay but an impulsive high-amplitude onset.

We found clear signals from five sustained and 20 impulsive events in the 51 hour long record. Both types occur only during times of overall rising water pressure, similar to what Kavanaugh (2009) observed for strong pressure pulses on Trapridge Glacier, Yukon, Canada. The amplitudes of our measured resonances vary between 200 and $1100 \mathrm{~Pa}$. Individual events cluster temporarily.

Impulsive events are occasionally accompanied by very short pressure pulses, lasting only a few milli seconds. One of these is shown in Fig. 2b, which is an unfiltered zoom into the gray shaded area of Fig. 2a. A superposed highfrequency peak that arrives $\sim 90 \mathrm{~ms}$ after the onset of the pressure oscillation can be seen. Plots showing the waveforms and the spectra of all recorded crack waves can be found in the Supplementary material.

The energy within the detected pressure oscillations is several orders of magnitude smaller than the energy in the fracture resonances in previous studies that were detected and recorded by their emitted seismic waves (Anandakrishnan and Alley, 1997; Winberry and others, 2009; Métaxian and others, 2003; Stuart and others, 2005; West and others, 2010). Consequently, a simultaneously deployed dense seismometer network at the glacier surface with a distance between stations of $\sim 100 \mathrm{~m}$ and one seismometer placed $\sim 120 \mathrm{~m}$ directly above the pressure sensor showed no seismic signature of the fracture resonances observed on the pressure sensor at the bed. From this we conclude that our recorded pressure oscillations are of much smaller magnitude than those detected in the previously mentioned studies, which show clear seismic signals.

\section{CHARACTERISTICS OF CRACK WAVES}

We interpret our resonant pressure oscillations as crack waves within the basal water layer sandwiched between the ice of the glacier from the top and the hard granite bedrock from below. Imagery from a co-located borehole camera supports this interpretation. The geometry of the basal conditions at the borehole terminus is schematically shown in Fig. 3a. The borehole with the pressure sensor connects directly to the water layer. The ice and rock react elastically to pressure oscillations within the water layer. Figure $3 \mathrm{~b}$ shows an image from a borehole camera at the location where the resonances were recorded. It is a top view onto the hard bedrock showing pebbles on the granite bed and clast protrusions behind the almost transparent ice of the borehole margins. The borehole image confirms the possibility that the ice at the bedrock may be supported by clasts (Creyts and Schoof, 2009). Furthermore it minimizes the possibility that the recorded crack wave resonances are accommodated within a channel or cavity since no three-dimensional (3-D) water-filled volume was present at the borehole terminus.

The thin water layer at the ice/bedrock interface is geometrically similar to a water-filled fracture, and thus lowfrequency resonances are expected to occur as pairs of counter-propagating crack waves along the finite extent of the water layer. Because the range of possible resonance wavelengths is constrained to be a multiple of the fracture length, crack waves propagating within the basal water layer show narrow-banded peaks in the frequency spectrum (Lipovsky and Dunham, 2015, Eqn(91)). 


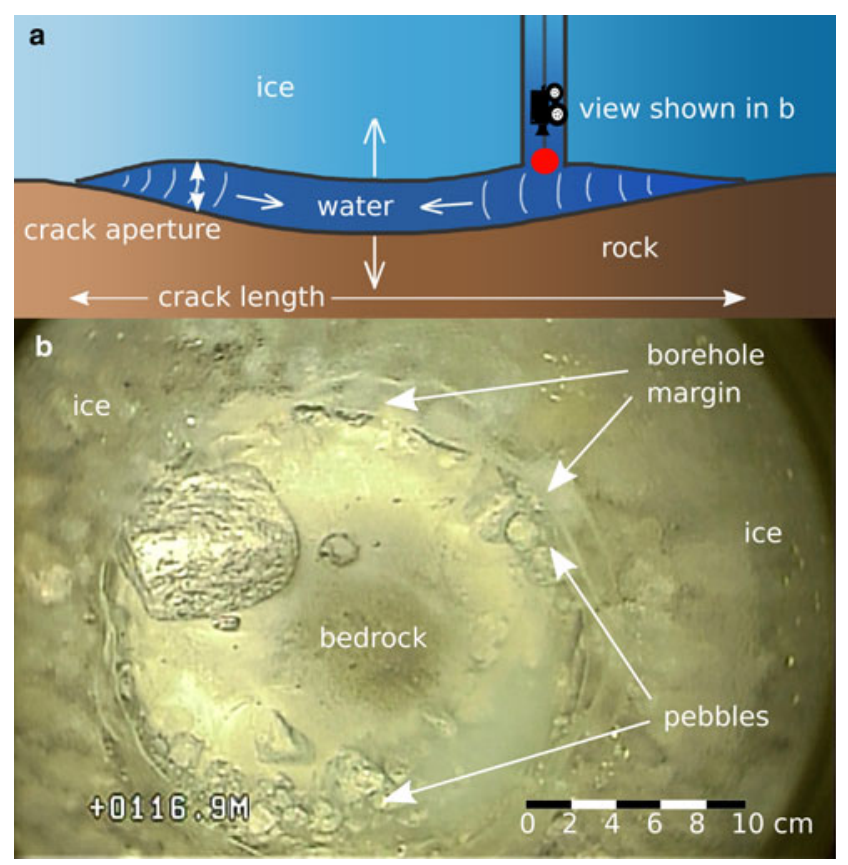

Fig. 3. (a) Scheme of crack waves within the basal water layer, a borehole camera and the pressure sensor (red dot), (b) top view from a borehole camera on the granite bedrock at the location of the pressure sensor.

Figure 4 shows the spectra of an example from the impulsive (red) and sustained (blue) crack waves. The gray dashed line shows the pre-event noise. The red and blue shaded areas indicate the one sigma error region of the mean spectra which represents the spectral content of the resonances best and shows the spectral peaks clearest. Both event types show distinct frequency peaks. Most prominent are the spectral peaks at $\sim 1,2$ and $4 \mathrm{~Hz}$ that are visible in both the impulsive and sustained events. However, the relative power in these peaks differs between impulsive and sustained events. Whereas the spectral energy within these three peaks increases with higher frequency for impulsive crack waves, leading to a dominant frequency of $\sim 4 \mathrm{~Hz}$, sustained crack waves have their dominant frequency at $\sim 1 \mathrm{~Hz}$ with a decreasing trend in the spectral power to higher frequencies. In addition, there exist two further peaks for the sustained events at $\sim 6$ and $8 \mathrm{~Hz}$ whereas the impulsive events have a broad, smeared-out peak at $\sim 12$ $\mathrm{Hz}$. Gray shaded regions denote the width of the five lower frequency peaks at $1 / \sqrt{2}$ of the peak amplitude calculated from the full ensemble of events as described below (see also Supplementary material).

The clear peak in the spectrum of sustained events at $\sim 8$ $\mathrm{Hz}$ that is not clearly visible in the impulsive events might be a hint that different modes are excited for different event types. This may be a source effect or a superposition of crack waves within different fractures or from different directions of the resonator volume. However, the similarity of the resonance frequencies occurring in the impulsive, as well as in the sustained crack wave resonances, is a strong indicator for a common resonance effect.

\section{Borehole resonances}

The borehole itself is an artificial water cavity that is capable of hosting resonances. To show that the resonances we

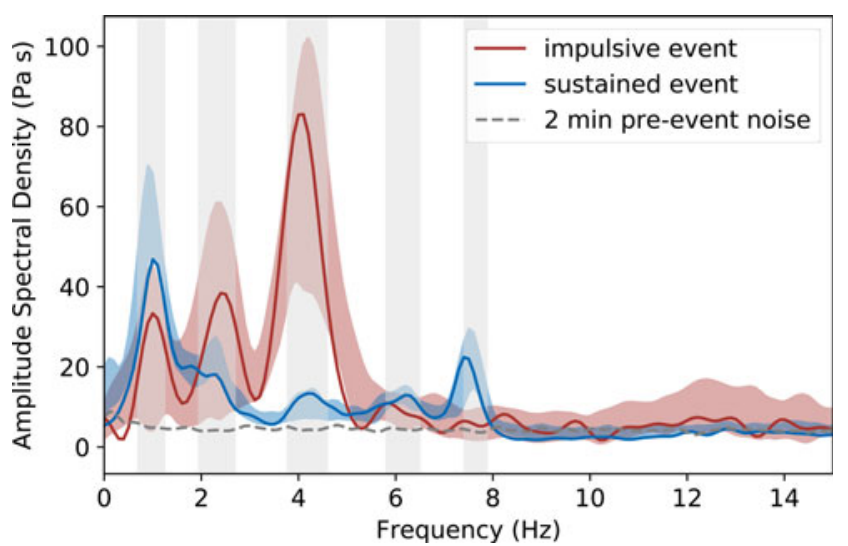

Fig. 4. Amplitude spectral density (ASD) of an example impulsive (red) and a sustained (blue) crack wave. The gray dashed line shows the pre-event noise level. Red and blue shaded areas indicate the one sigma uncertainty of the median ASD. Gray shaded regions mark the peak widths derived from a kernel density estimation (see Supplementary material).

measure are indeed crack waves traveling within the thin basal water layer and thereby justifying the use of the crack wave model of Lipovsky and Dunham (2015), we show in the following that we expect different frequency contents from pressure oscillations within the borehole.

Large pressure drops in the sub- and englacial water system are capable to excite resonances of the entire water column in the borehole. We expect these resonances to have a normal mode close to a harmonic oscillator of an open tube in a water reservoir with an angular frequency $\omega=\sqrt{g h^{-1}}$, where $g$ is the Earth's gravitational acceleration and $h$ is the height of the water column (for a derivation see Eqns (A 4a) to (A 4b)). Assuming a water level of 100 $\mathrm{m}$, which is similar to the water column we measure in the borehole, we expect a resonance frequency of order $0.1 \mathrm{~Hz}$ or less.

Resonances in water-filled fractures within the ice or at the bed can lead to so-called 'tube waves' within an intersecting borehole (Liang and others, 2017). These travel within the borehole and interact with the elastic margins of it. For the tube waves, we expect resonance frequencies following the modes similar to an organ pipe $f_{n}=4 n c_{t} h^{-1}$ with $n=1,2,3, \ldots$ and the tube wave velocity $c_{t}$ (Eqns (1) \& (2) in Roeoesli and others, 2016; Biot, 1952). By using a tube wave velocity of $c_{t}=1100 \mathrm{~ms}^{-1}$, determined by Eqn (A 3), this leads to a fundamental frequency of $f_{1}=2.75 \mathrm{~Hz}$ again with a water column of $100 \mathrm{~m}$. Although some of the overtones we measured are of the same order of magnitude, the measured low fundamental frequency in the pressure oscillations cannot be explained by water column resonances and tube waves for our case. Moreover, we expect a wave that is strong enough to excite a resonance in the borehole by traveling up and down the entire borehole water column multiple times to be detectable with our surface seismometer array similar to what has been observed for seismic moulin tremor by Roeoesli and others $(2014,2016)$.

\section{Dispersion of crack waves}

Due to the interaction with the elastic walls, crack waves are dispersive and thus the overtones of the resonance are 
non-integer multiples of each other, enabling us to test if the resonances we measure are indeed crack waves. For closed fractures, possible resonant wavelengths are $\lambda_{n}=2 \mathrm{Ln}^{-1}$ with $n=1,2,3, \ldots$ and the crack length $L$, and resonant frequencies $f_{n}=c\left(\lambda_{n}\right) \lambda_{n}^{-1}$ (Lipovsky and Dunham, 2015). This leads to an increasing spacing between the frequency peaks $f_{n} / f_{1}=n^{3 / 2}$ for crack waves. Our pressure oscillations do not perfectly follow the theoretical exponent of $3 / 2$. From an ensemble analysis (see Supplementary material) of single crack wave events, we determine the fundamental frequency to $f_{1}=0.98 \mathrm{~Hz}$ with a standard deviation of $\sigma_{f 1}=0.05 \mathrm{~Hz}$ and for the overtones $f_{2}=2.30 \mathrm{~Hz}, \sigma_{f 2}=0.11 \mathrm{~Hz}, f_{3}=$ $4.18 \mathrm{~Hz}, \sigma_{f 3}=0.08 \mathrm{~Hz}, f_{4}=6.14 \mathrm{~Hz}, \sigma_{f 4}=0.19 \mathrm{~Hz}, f_{5}=$ $7.61 \mathrm{~Hz}, \sigma_{f 5}=0.19 \mathrm{~Hz}$. This leads to an exponent in the dispersion relation of $n \approx 1.3$ compared to 1.5 in the model of Lipovsky and Dunham (2015). However, it has to be emphasized that the equations represent an idealized setup by assuming a spatially uniform aperture of the crack and a surrounding homogeneous material (for further discussions of this topic, see Lipovsky and Dunham (2015)). We apply this model to a setup at a bi-material interface where the fracture is supported by protrusions, whereas Lipovsky and Dunham (2015) assumed that the aperture was supported entirely by a water pressure in excess of the overburden pressure. In any case, since our overtones in the spectrum do not represent integer multiples of the fundamental frequency, the measured resonances show a dispersive behavior. Thus we conclude that they plausibly represent crack waves within the thin basal water layer between the ice and the bedrock.

\section{WATER LAYER PATCH SIZE}

We use the crack wave resonances to estimate the extension of the resonant basal water layer patch using Eqns (A1) and (A2). The resonator length is determined to be $L=19.8 \mathrm{~m}$ with a standard deviation of the single measurements of $\sigma_{L}=1.8 \mathrm{~m}$ and a systematic uncertainty of $\Delta L_{\text {sys }}=6 \mathrm{~m}$ due to the bi-material interface (systematics are described later in this section). The aperture is calculated to $w=1.1 \mathrm{~mm}$ with $\sigma_{w}=0.3 \mathrm{~mm}$. We give the standard deviation of the single value here, because the crack aperture, and probably also the crack length, vary with different water pressures as described in the section 'TRANSIENT PRESSURE CHANGES'. In the following, we outline the calculation of the aforementioned dimensions.

The elastic material properties and the geometry of the resonance volume govern the normal modes that can be excited within it. Since the material properties of ice, granite and water are known, we can estimate the water layer volume from the measured crack waves. In order to do so, the frequency content of the resonances and the spectral peak width, reflecting the resonance attenuation, has to be analyzed (Compare to Eqns (1) and (2) as well as Eqns (A1) and (A2)).

We carry out peak detection for each crack wave spectrum followed by a fit of a Gaussian for each peak to determine the peak position $f_{n}$ together with its width $\Delta f_{n}$ defined as the full width at half maximum of the energy spectrum (units of $\mathrm{Pa}^{2}$ ). Due to changing hydrostatic pressures during the observation times of the crack waves, the resonance frequencies and peak widths of individual events may change over time. A kernel density estimation (KDE) with a width of $0.3 \mathrm{~Hz}$ is applied to the collection of all detected peak positions. Subsequently, another Gaussian fit is applied to the peaks in the KDE. From the width of these Gaussians, frequency ranges for the overtones of interest are determined. As the last step, all the Gaussians fitted to the peaks in the spectrograms of individual crack waves that lie within the determined frequency intervals from the $\mathrm{KDE}$ are taken to calculate a mean of the peak frequencies, a mean of the peak widths, and their standard deviations. The detailed analysis is described in the Supplementary material.

There is an ambiguity in distinguishing the fundamental mode $f_{1}$, which is important for an estimation of the fracture size, because our measurements do not follow exactly the expected dispersion relation from the model of Lipovsky and Dunham (2015). Thus we cannot easily use the overtones of the crack waves for calculation of the resonance volume. We suggest that the spectral peak at $\sim 1 \mathrm{~Hz}$ reflects the fundamental frequency. This might not be immediately clear from the spectra and the waveforms of the impulsive events (compare to Fig. 2b), where this frequency could also be associated with the signal envelope. However, the fact that the same frequency peak $\sim 1 \mathrm{~Hz}$ occurs also for the sustained crack waves, supports the assumption that this peak is indeed the fundamental frequency. With the ensemble of crack waves that we analyzed, we determine the fundamental frequency is $f_{1}=0.98 \mathrm{~Hz}$ with a standard deviation of the single peaks of $\sigma_{f 1}=0.05 \mathrm{~Hz}$. The peak width is $\Delta f_{1}=0.64 \mathrm{~Hz}$ with $\sigma_{\Delta f 1}=0.17 \mathrm{~Hz}$, which leads to a quality factor $Q_{f 1}=f_{1} \Delta f_{1}^{-1}=1.5$ with $\sigma_{Q_{f 1}}=0.4$

The model of Lipovsky and Dunham (2015) describing crack wave propagation does not account for a resonator volume between half spaces with differing elastic properties. This setup is needed for a proper description of the crack waves within the basal water layer. In the model, the elastic plain strain modulus is only used for the calculation of the crack length, but not for the crack aperture, because the attenuation due to radiation of seismic energy at the walls is not included in the model we use, and is different from other models, which include seismic wave scattering (Frehner, 2013; Liang and others, 2017; O'Reilly and others, 2017). As a result, we expect a factor of two in the crack length estimation for pure rock compared to pure ice (compare the elastic plain strain moduli in Eqn (A2)) This factor arises from the different shear moduli and Poisson's ratios of ice and the granite bedrock (see Appendix B). For the quantitative size estimation of the basal water layer patch, we take the mean of the resonator volume estimation for pure ice and pure granite and report the difference to each end-member case as a systematic uncertainty $\Delta L_{\text {sys }}$.

In three dimensions, the crack length from the 2-D model of Lipovsky and Dunham (2015) corresponds to the maximum 2-D extension of the resonator. Equations (A1) and (A2) together with the physical parameters of ice, rock and water (see Appendix B) lead to a length estimation of the basal water layer patch of $L=19.8 \mathrm{~m}$ with a standard deviation of the single measurements of $\sigma_{L}=$ $1.8 \mathrm{~m}$ and a systematic uncertainty of $\Delta L_{s y s}=6 \mathrm{~m}$. The aperture (thickness) of the basal water layer at our drilling site is determined independent of the elastic properties of the fracture walls to $w=1.1 \mathrm{~mm}$ with $\sigma_{w}=0.3 \mathrm{~mm}$. A table of the extension of the water layer patch calculated from the overtones can be found in the Supplementary material. 


\section{TRANSIENT PRESSURE CHANGES}

We infer an increasing water layer aperture that occurs coincident with a simultaneous rise in hydrostatic pressure. The estimated change in aperture is between 2 and $40 \%$ within 20 minutes. These coincident phenomena are consistent with an expected increase in basal water layer thickness due to elevated buoyancy forces. In the following we describe our quantitative estimation of the increasing aperture:

Figure 5 shows the transient evolution of the hydrostatic pressure at the glacier bed from $101.5 \mathrm{~m}$ water column to $102.1 \mathrm{~m}$ water column over a period of 20 minutes starting at 22 August 2017, 10:08 am. At our site, the $117 \mathrm{~m}$ ice reaches flotation level at a water column of $107 \mathrm{~m}$. During these 20 minutes, five sustained and four impulsive crack waves occur. Immediately before the second impulsive crack wave, a pressure drop of $\sim 500 \mathrm{~Pa}(5 \mathrm{~cm}$ water column) appears.

In the spectra of the sustained events, shown in Fig. 5b, an increase in the frequency content of the overtone below $8 \mathrm{~Hz}$ can be seen. A similar behavior has been observed by Heeszel and others (2014) where resonance frequencies from hydro-fractures, recorded with surface seismometers, also increased over time. The authors explain this increase by a closing of the crack, which contrasts with our interpretation. This inconsistency may arise from the fact that Heeszel and others (2014) did not take the attenuation of the signal into account, which plays a critical role for crack waves.

From the relative changes in the frequency content of the sustained crack waves in Fig. 5b it is clear that the geometry of the resonating volume must change. Eqns (1) and (2), which are also valid for overtones with $f_{n}$ and $\Delta f_{n}$, predict that not only the frequency of the resonant peaks, but also their widths are affected by a changing crack geometry. While in the spectrogram in Fig. $5 b$ a shift of the spectral peak of the overtone in the frequency band between 7.5 and $8 \mathrm{~Hz}$ from lower to higher frequencies can be seen, it

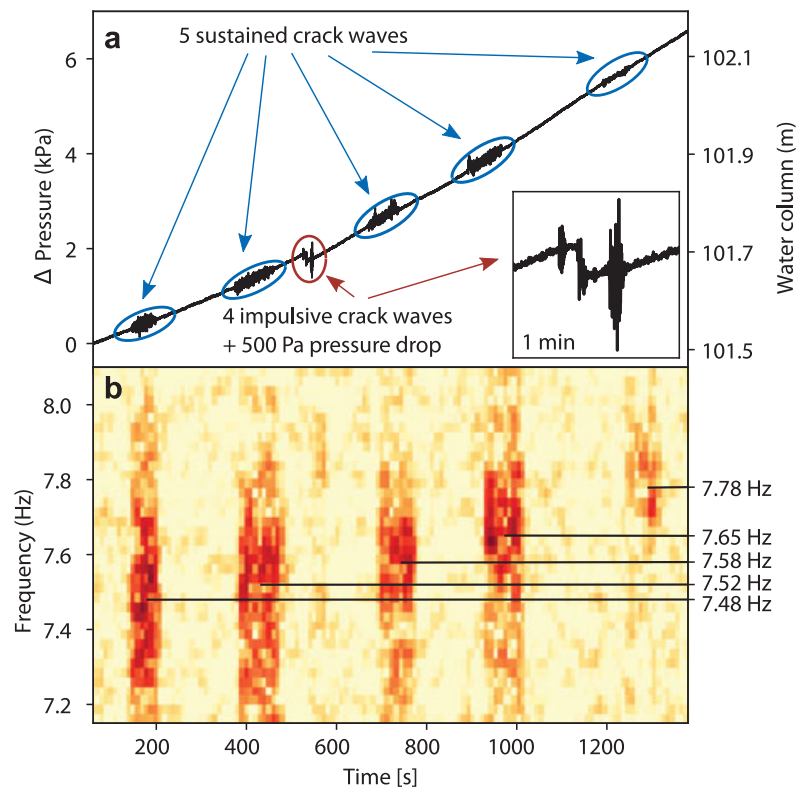

Fig. 5. (a) Temporal evolution of the relative pressure during the occurrence of five sustained crack waves within 20 minutes. (b) Spectrogram of one overtone between 7.2 and $8 \mathrm{~Hz}$. is difficult to make statements about the peak width due to the limited frequency resolution in the spectra. From the peak analysis, a continuous increase in the peak frequency from 7.48 to $7.78 \mathrm{~Hz}$ can be determined. However, the peak width varies between 0.22 and $0.30 \mathrm{~Hz}$ with a decreasing trend. Assuming that there is no change in the width of the overtone, we estimate a minimal change in basal water layer aperture of $\Delta w=2 \%$ within 20 minutes. With this assumption, the length of the water layer patch would shrink by the same amount since both scale with the square root of the frequency. Including the trend in the spectral width of the overtone, the changes would be one order of magnitude larger with $\Delta w=40 \%$ and $\Delta L=9 \%$.

\section{RESONANCE EXCITATION AND PRESSURE DROP}

There are various candidates for resonance-exciting processes ranging from sudden basal cavity growth in response to stick-slip events (Zoet and others, 2013) or tensile faulting, (Walter and others, 2013) to abrupt changes in fluid motion (Ferrick and others, 1982; Julian, 1994, although note countervailing analysis by Dunham and Ogden, 2012). Since our study focuses on observed resonances rather than the processes which excite them, we only briefly touch on some of these aspects. Pin-pointing the exact excitation processes requires additional analysis and data, and is subject of ongoing investigation.

The high-frequency pressure pulse shown in Fig. 2c occasionally accompanies impulsive crack wave events, and may give further information on the triggering mechanism. Although we have not investigated this systematically yet, we suggest it is a non-dispersive sound wave traveling within the resonance volume of the basal water layer. However, we do not have an explanation for the delayed occurrence of the sound waves with respect to the onset of the crack wave resonances. The impulsivity of the sound waves in the pressure recordings hints towards an abrupt excitation mechanism such as a microseismic basal stickslip event.

Crack waves that accompany rapid ( $\sim \mathrm{ms})$ pressure drops support the theory that basal microseismic stick-slip motion may be a possible trigger mechanism of impulsive crack waves. In Fig. 5a, a small pressure drop of $\sim 500 \mathrm{~Pa}$ ( $5 \mathrm{~cm}$ water column) between the impulsive crack waves can be seen, while the overall hydrostatic pressure continuously increases. A similar event with a $2300 \mathrm{~Pa}(23 \mathrm{~cm}$ water column) pressure drop occurs 4 hours later (pressure curve in Supplementary material). In both cases, impulsive crack waves and other pressure oscillations similar to crack waves occur concurrently. The volume change producing a water column drop of 5 and $23 \mathrm{~cm}$ respectively, can be estimated from the geometry of the borehole, which has a diameter of $\sim 15-20 \mathrm{~cm}$. Assuming a weakly connected system, the opened volume is $\sim 0.9-1.6$ liter for the smaller pressure drop event and 4-7 liter for the larger one.

The simultaneous occurrence of impulsive crack waves in both cases together with the basal water pressure drop may be evidence for a microseismic stick-slip episode of glacier sliding (Zoet and others, 2013; Meierbachtol and others, 2018): As a result of increasing water pressure caused by the diurnal melt cycle, decreasing effective pressure at the ice/bedrock interface decreases basal friction on stickyspots (Fischer and Clarke, 1997) near our pressure sensor. This means that shear stress accumulated at the ice/ 

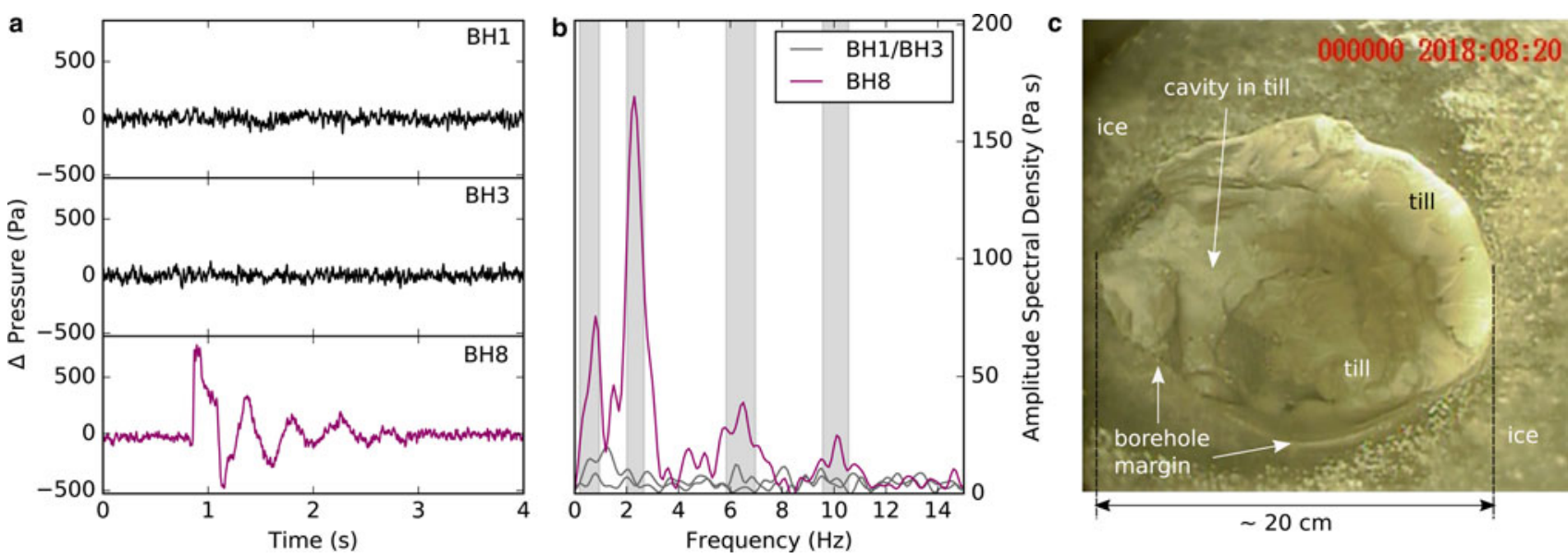

Fig. 6. (a) Waveform of a crack wave recorded at one borehole pressure sensor (BH 8). (b) Spectrum of the crack wave. (c) Footage of a neighboring borehole showing an at least $10 \mathrm{~cm}$ thick silt layer.

bedrock interface can exceed the decreasing frictional resistance, leading to stick-slip sliding triggering impulsive crack waves. A sudden volume change resulting from volume increase of water-filled cavities behind undulations in the bedrock during these stick-slip events causes the subglacial pressure drop.

Due to the temporal swarming behavior of the measured crack waves and the few events we have in our data, it is not possible to confirm with our crack wave data the prediction of Lipovsky and Dunham (2017) that the increasing hydrostatic pressure results in a shorter recurrence time of stick-slip events leading to a higher seismicity. This could have provided evidence for a relation between the crack waves and basal stick-slip events. However, the observation that crack waves in our data only occur with rising water pressure may indicate a link between increasing water pressure and basal seismicity from microseismic stick-slip events.

On recordings of a seismometer array (A field area map is in the Supplementary material.) that was deployed during our in-situ basal water pressure measurements, we could not find a signal of a basal stick-slip event during the pressure drops. One possible explanation could be that the stick-slip events causing the pressure drop and the crack waves were too small to be detected at the glacier surface.

\section{SUMMARY AND OUTLOOK}

The interpretation of the pressure signals as crack waves within the basal water layer was based on the following observations: The sustained and the impulsive pressure oscillations were recorded directly at the hard granite bedrock. Both show resonant behavior and they furthermore share common resonance frequencies, indicating a common resonance effect (i.e. crack waves). Non-equally spaced overtones support the interpretation of the pressure resonances as crack waves. Applying the formalism of Lipovsky and Dunham (2015) yields a reasonable thickness for the basal water layer, increasing with higher basal water pressures as expected for basal water pressure approaching flotation level. Further detected signals such as nearly instantaneous pressure drops and sound waves give hints towards a stickslip related trigger mechanism.

In 2018, we carried out similar measurements to 2017 but further up-glacier and with multiple pressure sensors. From these, we see indications that crack waves at the bed are not a unique phenomenon of the 2017 drilling site, but may be universal. Among many transient pressure pulses, drops and oscillations in the continuous 18-day-long data from 2018, we also found crack-wave-like events that are comparable to those measured lower on the tongue in 2017. (A field area map of the 2018 boreholes is in the Supplementary material. The position of the field site can be seen in Fig. 1)

Figures $6 \mathrm{a}$ and $\mathrm{b}$ show one of these potential crack wave signals from the 2018 dataset. As we had two additional simultaneously recording pressure sensors deployed that do not show any signal within a distance of 2.5 and $5 \mathrm{~m}$ from the sensor that recorded a signal, we suggest that the recorded resonance is a highly localized phenomenon at the glacier bed. Figure $6 c$ shows borehole camera footage of the glacier bed in the direct vicinity of the crack wave resonator. Different from Fig. 3, a $\sim 10 \mathrm{~cm}$ silt layer that can change within timescales of hours (see video in the Supplementary material) and that has the ability to tightly close water-filled volumes thus separating the resonator from the boreholes 1 and 3, may explain this observation. However, from the recorded resonance showing a dispersive frequency ratio of $n^{1.3}-n^{1.5}$ similar to the 2017 crack waves, we can estimate a resonance volume length of $L \approx 12 \mathrm{~m}$ and a water layer thickness of $w \approx 1.7 \mathrm{~mm}$ which is comparable to the dimensions of the water layer patch measured lower on the glacier tongue. These measurements propose that using pressure resonances at the glacier bed is a promising method to study spatial and temporal variations of the basal water layer.

Although our results represent only point measurements, the length scales of the estimated water layer patches fit well to undulations in the bedrock that can be observed at the recently de-glaciated area of Rhonegletscher (see Supplementary material). Accordingly, basal water layer patches may form between bedrock bumps on which the weight of the overlying ice concentrates.

The thickness of the basal water layer of 1-2 $\mathrm{mm}$ that we determined is larger than previously estimated using sediment distributions to $\sim 100 \mu \mathrm{m}$ by Hallet (1979). However, Hallet acknowledges that locally the thickness can be higher by a factor of 100 . Indirect measurements of the water layer above an artificial till cavity at the subglacial laboratory at Engabreen show a thickness of up to $0.25 \mathrm{~mm}$ (Iverson and others, 2007). On the theoretical side, Walder (1982) calculates that the water layer thickness must be 
$<5 \mathrm{~mm}$ for glaciers $<100 \mathrm{~km}$ long, whereas Weertman (1972) calculates millimeter-thick water layers for glaciers in the same size class as Rhonegletscher. Our in-situ measurements of the water layer thickness at our drilling site match these predictions well and represent a new method to investigate the extension and morphology of the basal water layer.

\section{CONCLUSION}

Kilohertz-sampled pressure measurements in the direct vicinity of the glacier bed of Rhonegletscher show resonant pressure oscillations with non-equally spaced overtones. We interpret these resonances as crack wave resonances within the basal water layer. A systematic relation between the resonant frequencies of these crack waves, their spectral width and a transient subglacial water pressure evolution was found. From these crack waves, the local thickness of the basal water layer and the extension of water layer patches that host the observed crack waves were determined. The results show that the basal water layer is sufficiently patchy to host crack wave resonances, and that it is a dynamic system, influenced by hydrostatic pressure changes.

\section{DATA AVAILABILITY}

In the future, the presented dataset will be made publicly available on the servers of the Swiss Seismological Service (http://seismo.ethz.ch). The network name is ' $4 \mathrm{D}$ ' and the station name is 'RA01 P'. In the meantime the dataset is available on request from the author. The python code for the data analysis is included in the Supplementary material.

\section{SUPPLEMENTARY MATERIAL}

The supplementary material for this article can be found at https://doi.org/10.1017/aog.2019.8

\section{ACKNOWLEDGMENTS}

We thank the two anonymous reviewers for their constructive comments on this paper and our colleagues at VAW for their great support in the field. Financial support was provided by the Swiss Federal Institute of Technology (ETH Zurich) via Grant ETH-06 16-12 and the ETH Scientific Equipment Program as well as the Swiss National Science Foundation (Grant PP00P2_157551).

\section{REFERENCES}

Aki K, Fehler M and Das S (1977) Source mechanism of volcanic tremor: fluid-driven crack models and their application to the 1963 Kilauea eruption. J. Volcanol. Geotherm. Res., 2(3), 259287, ISSN 0377-0273

Anandakrishnan S and Alley R (1997) Tidal forcing of basal seismicity of ice stream c, west Antarctica, observed far inland. J. Geophys. Res. Solid Earth, 102(B7), 15183-15196, ISSN 21562202

Bauder A, Funk M and Huss M (2007) Ice-volume changes of selected glaciers in the Swiss alps since the end of the 19th century. Ann. Glaciol., 46, 145-149

Bean CJ and 5 others (2014) Long-period seismicity in the shallow volcanic edifice formed from slow-rupture earthquakes. Nat. Geosci., 7(1), 71
Biot MA (1952) Propagation of elastic waves in a cylindrical bore containing a fluid. J. Appl. Phys., 23(9), 997-1005, ISSN 00218979

Clarke GK (2005) Subglacial processes. Annu. Rev. Earth Planet. Sci., 33, 247-276, ISSN 0084-6597

Creyts TT and Schoof CG (2009) Drainage through subglacial water sheets. J. Geophys. Res. Earth Surf., 114(F4), F04008, ISSN 21562202

Dunham EM and Ogden DE (2012) Guided waves along fluid-filled cracks in elastic solids and instability at high flow rates. J. Appl. Mech., 79(3), 031020-031020-7

Ferrazzini $V$ and Aki K (1987) Slow waves trapped in a fluid-filled infinite crack: Implication for volcanic tremor. J. Geophys. Res. Solid Earth, 92(B9), 9215-9223, ISSN 2156-2202

Ferrick M, Qamar A and St Lawrence W (1982) Source mechanism of volcanic tremor. J. Geophys. Res. Solid Earth, 87(B10), 86758683, ISSN 0148-0227

Fischer UH and Clarke GK (1997) Stick slip sliding behaviour at the base of a glacier. Ann. Glaciol., 24, 390-396, ISSN 0260-3055

Frehner M (2013) Krauklis wave initiation in fluid-filled fractures by seismic body waves. Geophysics, 79(1), T27-T35

GLAMOS (2018) The Swiss Glaciers 2015/16 and 2016/17, Bauder, A. (ed.), Glaciological Report No. 137/138 of the Cryospheric Commission (EKK) of the Swiss Academy of Sciences (SCNAT) published by VAW / ETH Zürich, doi: 10.18752/glrep_137-138.

Hallet B (1979) Subglacial regelation water film. J. Glaciol., 23(89), 321-334, ISSN 0022-1430

Heeszel DS, Walter F and Kilb DL (2014) Humming glaciers. Geology, 42(12), 1099-1102, ISSN 1943-2682

Iken A, Röthlisberger H and Hutter K (1976) Deep drilling with a hot water jet. Zeitschrift für Gletscherkunde und Glazialgeologie, XII (2), 143-156

Iverson NR (1999) Coupling between a glacier and a soft bed: li model results. J. Glaciol., 45(149), 41-53

Iverson NR and 7 others (2007) Soft-bed experiments beneath Engabreen, Norway: regelation infiltration, basal slip and bed deformation. J. Glaciol., 53(182), 323-340

Julian BR (1994) Volcanic tremor: nonlinear excitation by fluid flow. J. Geophys. Res. Solid Earth, 99(B6), 11859-11877, ISSN 21562202

Kavanaugh J (2009) Exploring glacier dynamics with subglacial water pressure pulses: evidence for self organized criticality? J. Geophys. Res. Earth Surf., 114(F1), F01021, ISSN 2156-2202

Kavanaugh JL and Moore PL (2010) A peak-capturing measurement circuit for detecting and recording short-duration glacial signals. J. Glaciol., 56(195), 41-47, ISSN 0022-1430

Krauklis P (1962) On some low-frequency oscillations of a liquid layer in elastic medium. $P M M, \mathbf{2 6}(6), 1685-1692$.

Liang C, O'Reilly O, Dunham EM and Moos D (2017) Hydraulic fracture diagnostics from Krauklis-wave resonance and tube-wave reflections. Geophysics, 82(3), D171-D186, ISSN 0016-8033

Lipovsky BP and Dunham EM (2015) Vibrational modes of hydraulic fractures: inference of fracture geometry from resonant frequencies and attenuation. J. Geophys. Res. Solid Earth, 120(2), 1080-1107, ISSN 2169-9356

Lipovsky BP and Dunham EM (2017) Slow slip events on the Whillans ice plain, Antarctica, described using rate and state friction as an ice stream sliding law. J. Geophys. Res. Earth Surf., 122 (4), 973-1003, ISSN 2169-9011

Meierbachtol TW, Harper JT and Humphrey NF (2018) Short duration water pressure transients in western greenland's subglacial drainage system. J. Glaciol., 64(243), 171-174, ISSN 0022-1430

Métaxian J, Araujo S, Mora M and Lesage P (2003) Seismicity related to the glacier of Cotopaxi volcano, ecuador. Geophys. Res. Lett., 30(9), 1483, ISSN 1944-8007

O'Reilly O, Dunham EM and Nordstrm J (2017) Simulation of wave propagation along fluid-filled cracks using high-order summationby-parts operators and implicit-explicit time stepping. SIAM. J. Sci. Comput., 39(4), B675-B702 
Petrenko VF and Whitworth RW (1999) Phys. Ice. Oxford, UK: OUP Oxford

Podolskiy EA and Walter F (2016) Cryo seismology. Rev. Geophys., 708-758, ISSN 1944-9208

Rada C and Schoof C (2018) Channelized, distributed, and disconnected: subglacial drainage under a valley glacier in the Yukon. Cryosphere, 12(8), 2609-2636, ISSN 1994-0416

Roeoesli C and 6 others (2014) Sustained seismic tremors and icequakes detected in the ablation zone of the Greenland ice sheet. J. Glaciol., 60(221), 563

Roeoesli C, Walter F, Ampuero J and Kissling E (2016) Seismic moulin tremor. J. Geophys. Res. Solid Earth, 121(8), 5838-5858, ISSN 2169-9356

Stuart G, Murray T, Brisbourne A, Styles P and Toon S (2005) Seismic emissions from a surging glacier: Bakaninbreen, Svalbard. Ann. Glaciol., 42, 151-157, ISSN 0260-3055

Walder JS (1982) Stability of sheet flow of water beneath temperate glaciers and implications for glacier surging. J. Glaciol., 28(99), 273-293, ISSN 0022-1430

Walter F, Dalban Canassy P, Husen S and Clinton JF (2013) Deep icequakes: what happens at the base of alpine glaciers? J. Geophys. Res. Earth Surf., 118(3), 1720-1728, ISSN 2169-9011

Weertman J (1972) General theory of water flow at the base of a glacier or ice sheet. Rev. Geophys., 10(1), 287-333, ISSN 8755-1209

West ME, Larsen CF, Truffer M, O'Neel S and LeBlanc L (2010) Glacier microseismicity. Geology, 38(4), 319-322, ISSN 1943-2682

Winberry JP, Anandakrishnan S and Alley RB (2009) Seismic observations of transient subglacial water flow beneath Macayeal ice stream, west Antarctica. Geophys. Res. Lett., 36(11), L11502, ISSN 1944-8007

Zoet L, Alley R, Anandakrishnan S and Christianson K (2013) Accelerated subglacial erosion in response to stick-slip motion. Geology, 41(2), 159-162, ISSN 1943-2682

\section{APPENDIX A. EQUATIONS}

Fracture length from Lipovsky and Dunham (2015) in the crack wave limit with the kinematic viscosity of water $v$, the density of water $\rho_{0}$, the elastic plain strain modulus $G^{*}$, the fundamental frequency of the resonance $f_{1}$, and its attenuation factor $Q_{1}$ :

$$
L=\frac{1}{2}\left[\pi \nu\left(\frac{G *}{\rho_{0}}\right)^{2} \frac{Q_{1}^{2}}{f_{1}^{5}}\right]^{1 / 6}
$$

Full fracture aperture from Lipovsky and Dunham (2015) in the crack wave limit with the kinematic viscosity of water $v$, the fundamental frequency $f_{1}$ and its attenuation factor $Q_{1}$ :

$$
w=Q_{1} \sqrt{\frac{v}{\pi f_{1}}}
$$

Tube wave velocity from Roeoesli and others (2016) with the bulk modulus of water $b$, the shear modulus of ice $G$ and the density of water $\rho_{0}$ :

$$
c_{t}=\sqrt{\frac{G b}{\rho_{0}(G+b)}}
$$

Gravitational oscillations (angular frequency $\omega$ ) of a water column (mass $m_{\text {tot, }}$ density $\rho$ ) with height $h$ in a tube with diameter $r$, the earth acceleration $g$, and the water level deviation from the equilibrium position $y(t)$ :

$$
\begin{gathered}
F(t)=m_{\text {tot }} \ddot{y}(t)=\rho \pi r^{2} h \ddot{y}(t) \text { and } \\
F(t)=-\rho \pi r^{2} y(t) g \\
\rho \pi r^{2} h \ddot{y}(t)=-\rho \pi r^{2} g y(t) \underset{\text { oscillatory }}{\frac{\text { solution }}{\longrightarrow}} \omega=\sqrt{\frac{g}{h}}
\end{gathered}
$$

\section{APPENDIX B. PHYSICAL PARAMETERS}

List of physical parameters used for crack geometry determination and tube wave velocity (Lipovsky and Dunham, 2015; Petrenko and Whitworth, 1999):

Shear modulus: $G=3.8 \mathrm{GPa}$ for ice, $G=27 \mathrm{~Pa}$

Bulk modulus of water $b=1.98 \mathrm{GPa}$

Kinematic viscosity of water: $v=1.7 \cdot 10^{-6} \mathrm{~m}^{2} \mathrm{~s}^{-1}$

Poisson's ratio: $v_{s}=0.35$ for ice, $v_{s}=0.25$ for granite

Density of water: $\rho_{0}=1000 \mathrm{~kg} \mathrm{~m}^{-3}$ 